Gut, 1973, 14, 733-738

\title{
Inhibition of leucocyte migration by tumour- associated antigens of the colon and rectum
}

\author{
P. J. GUILLOU AND G. R. GILES \\ From the University Department of Surgery, Leeds (St James's) University Hospital, Leeds
}

SUMMARY The test of leucocyte migration inhibition has been used to detect lymphocyte sensitization to tumour-associated antigens of the colon and rectum. The procedure for the isolation of antigens from colorectal adenocarcinomata and normal colonic mucosa is described. The circulating lymphocytes of 22 patients suffering from colorectal adenocarcinomata of various stages have been examined and compared with the results obtained for identical studies performed on the peripheral lymphocytes of 15 control subjects. Sensitization of lymphocytes to tumour antigen was demonstrated in 15 of the 22 patients when culture was performed in homologous AB serum. Of these 15 patients only six showed inhibition of leucocyte migration in the presence of tumour extract when culture was performed in autologous serum. These observations would suggest the presence of factors in the serum of such patients which may prevent the expression of cellular immunity to tumour antigens.

Malignant neoplasms of the gastrointestinal tract possess surface antigens which may be capable of provoking delayed hypersensitivity responses (Gold and Freedman, 1965; Nairn, Fothergill, McEntegart, and Porteous, 1962; Nairn, Nind, Guli, Davies, Rolland, McGiven, and Hughes, 1971; Kleinman, Harwell, and Turner, 1971; Freed and Taylor, 1972). Attempts to demonstrate cellular hypersensitivity to these antigens using the technique of in-vitro blast transformation have not been successful (Lejtenyi, Freedman, and Gold, 1971) though Hellström, Hellström, Pierce, and Yang (1968) and Hellström, Sjögren, Warner, and Hellström (1971) were able to demonstrate direct lymphocyte cytotoxicity against tumour cells. The technique of leucocyte migration inhibition is a further test of cellular hypersensitivity to antigens (Rosenberg and David, 1970). In this study we have applied the technique to produce an index of delayed hypersensitivity to tumour-associated antigens in patients suffering from colorectal cancer. Since it is apparent that the serum of patients with cancer may interfere with immunological reactions against antigens (Hellström, Hellström, Evans, Heppner, Pierce, and Yang, 1969; Hellström et al, 1969) the tests have been performed in both autologous and homologous AB serum.

Received for publication 31 May 1973.

\section{Materials and Methods}

\section{CLINICAL GROUPS}

Leucocyte migration studies designed to investigate sensitization to tumour antigens were carried out in 22 patients with adenocarcinoma of the rectum or colon and were compared with the results of similar studies in 15 healthy volunteers. The mean age of the patients with cancer was 63 years (range 46 to 84 years) and that of the volunteer subjects was 46.7 years (range 26 to 74 years). Using the staging classification of recto-colonic carcinoma devised by Dukes (1957), 13 of the patients were found to have distant metastases (D cases) and eight patients had nodal involvement only ( $\mathrm{C}$ cases). In one patient the tumour had penetrated only the muscle coat (B case).

\section{TECHNIQUE OF LEUCOCYTE MIGRATION} INHIBITION

Peripheral blood leucocytes were separated from 20 $\mathrm{ml}$ of defibrinated venous blood by sedimentation with one half the volume of dextran 150 in $0.9 \%$ saline (Dextraven 150, Fisons Ltd). This procedure separates 95 to $98 \%$ of all the leucocytes from the blood, of which approximately $4 \%$ are monocytes. 50 to $60 \%$ are polymorphs, and the remainder are lymphocytes. The leucocytes were then washed at least four times in TC 199 (Burroughs Wellcome 
Ltd) prepared at a $\mathrm{pH}$ of $7 \cdot 4$ without the addition of antibiotics. The leucocyte suspension was adjusted to a concentration of $10^{8}$ cells per $\mathrm{ml}$ and drawn up into $10 \mu \mathrm{l}$ capillary tubes (Drummond Microcaps, Drummond Scientific Co, USA) which were then heat-sealed at one end. The tubes were centrifuged at $500 \mathrm{rpm}$ for five minutes and then cut at the cellfluid interface. The leucocyte-containing portions were placed in the wells of micro tissue-culture plates (Sterilin Ltd) with the open end of the tube facing centrally. After each well had been filled with medium $(0.5 \mathrm{ml}$ per well approximately), it was covered with a sterile cover slip and sealed by silicone grease. All cultures were incubated for 20 hours at $37^{\circ} \mathrm{C}$.

For each subject studied capillaries were prepared in quadruplicate for incubation in each of the following media: (1) $10 \%$ homologous $\mathrm{AB}$ serum in TC 199; (2) 10\% homologous AB serum in TC 199 with the addition of normal colonic mucosal extract; (3) $10 \%$ homologous $\mathrm{AB}$ serum with the addition of tumour extract; (4) $10 \%$ autologous serum in TC 199; (5) $10 \%$ autologous serum in TC 199 with the addition of normal colonic mucosal extract, and (6) $10 \%$ autologous serum with the addition of tumour extract.

The areas of leucocyte migration from the free ends of the capillary tubes were measured by planimetry after projection onto paper at a constant magnification. The mean area of leucocyte migration for each group of four capillaries was then calculated. Migratory indices were obtained by dividing the mean area obtained for incubation in the presence of tissue extract by the mean area obtained in the absence of tissue extract, ie, migratory index $=\frac{M x}{M o}$.

The homologous $\mathrm{AB}$ serum was obtained from a pool of seven healthy donors. Tissue extracts were added to the media at a concentration of $50 \mu \mathrm{g}$ protein per $\mathrm{ml}$ of medium.

Multiple experiments were also performed using the leucocytes of three healthy subjects to determine the concentration of extract at which non-specific inhibition of migration might occur. Significant inhibition of migration was not observed in these cultures until the concentration of tissue extract had exceeded $150 \mu \mathrm{g}$ of protein per $\mathrm{ml}$ of medium.

PREPARATION OF THE TISSUE EXTRACTS

Samples of rectal or colonic adenocarcinomata were obtained from fresh operative specimens and stored at $-20^{\circ} \mathrm{C}$ until use. Samples were then pooled and, following homogenization for one hour in a sealed unit homogenizer (Silverson), a perchloric acid extract was prepared after the method of Freed and

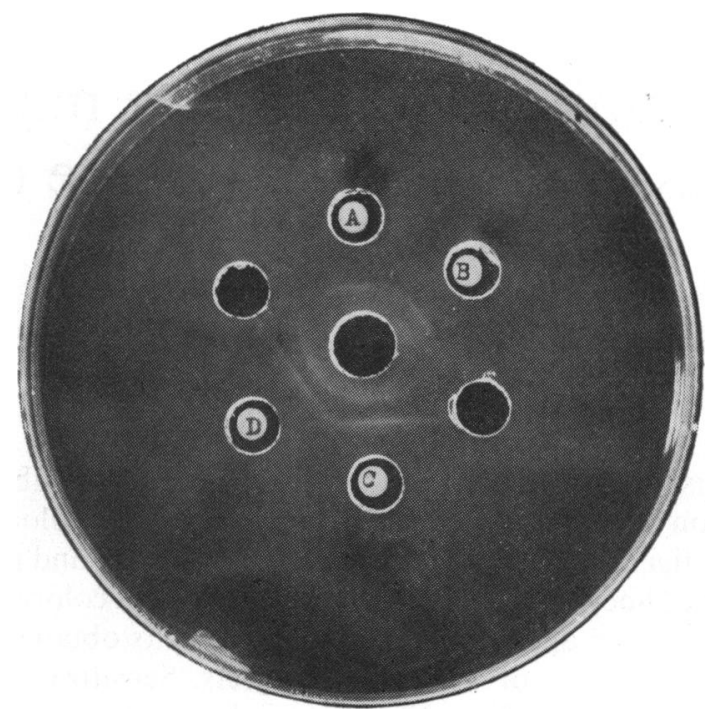

Fig 1 Ouchterlony immunodiffusion plate demonstrating the presence of tumour-associated antigens.

Centre well Rabbit antiserum against a perchloric acid extract of colorectal carcinomata.

Wells A and B Solution ( $0.1 \mathrm{mg}$ of protein per $\mathrm{ml})$ of perchloric acid extract of normal colonic mucosa.

Wells C and D Solution $(0.1 \mathrm{mg}$ of protein per $\mathrm{ml})$ of perchloric acid extract of colorectal carcinomata.

Taylor (1972). Normal colonic mucosa was obtained from the same resected specimens at a site at least $10 \mathrm{~cm}$ away from the tumour and subjected to the same procedure as the tumour tissue. Following ultracentrifugation and dialysis the supernatants from each extract were lyophilized and stored at $4^{\circ} \mathrm{C}$. The protein content of each extract was estimated by the method of Lowry, Rosebrough, Farr, and Randall (1951).

Antisera to tumour tissue extract and normal colonic mucosal extract were raised in rabbits and the presence of tumour-associated antigens was demonstrated by the technique of Ouchterlony double-diffusion in Noble agar (fig 1). Immunodiffusion procedures were performed on each sample of antigen prepared in order to ensure the continued isolation of antigen from each pool of tumour obtained.

\section{Results}

In these studies the migratory indices obtained for the control subjects have been used to establish the normal range of migratory inhibition on exposure to the two tissue extracts in each serum. Thus the $95 \%$ confidence limits (mean \pm 2 standard deviations) 
were calculated for all four sets of results obtained for the control group. The migration indices obtained for the patients were then examined with particular reference to those which fell below the lower 2.5 percentile for the range of results obtained for the control group. Those results falling below this limit were then taken to indicate a positive response to the tissue extract.

\section{CULTURE IN HOMOLOGOUS AB SERUM}

The mean migratory index for the control subjects in the presence of normal colonic mucosal extract was 1.04 with a standard deviation of 0.125 . The lower 2.5 percentile limit for this group was therefore $0 \cdot 79$. Five patients with colorectal cancer exhibited migratory indices with normal colonic mucosal extract which were below this figure (fig 2).

The mean migratory index for control subjects

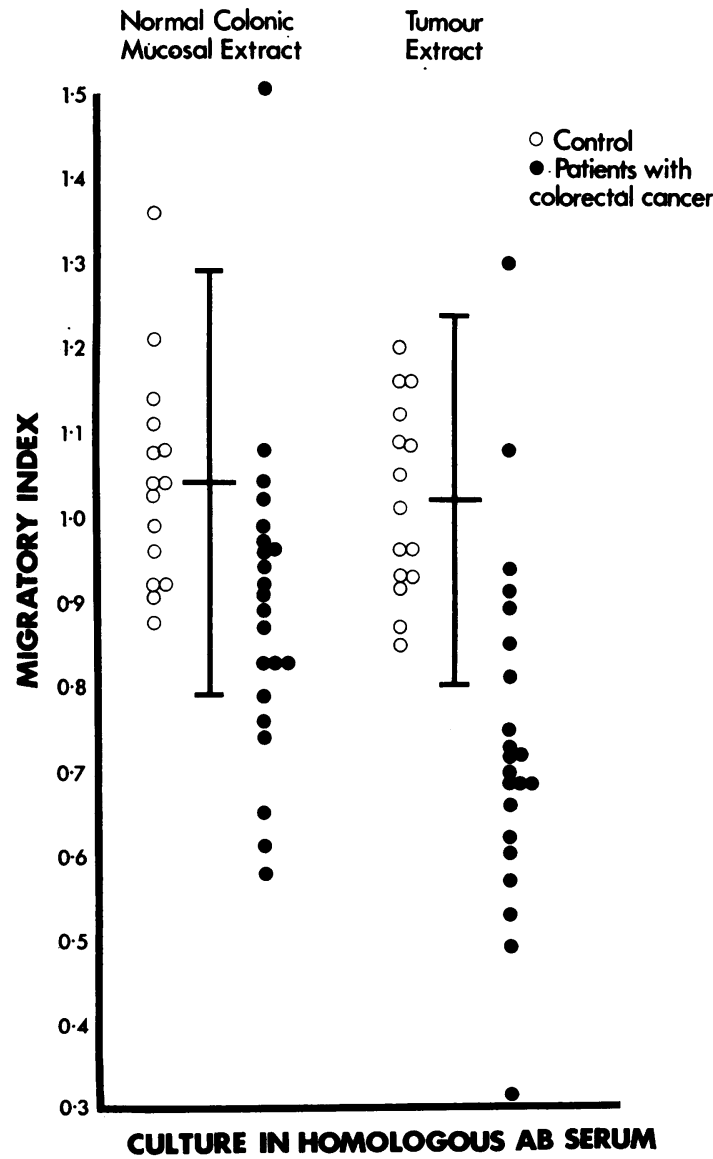

Fig 2 Leucocyte migratory indices obtained when culture was performed in homologous $A B$ serum. Vertical lines indicate the mean $\pm 2 \times$ standard deviations of the results obtained for the control group of subjects. when their leucocytes were cultured in the presence of tumour extract was 1.02 with a standard deviation of 0.11 and a lower 2.5 percentile of 0.8 . Fifteen of the 22 patients with colorectal cancer whose leucocytes were cultured under identical conditions exhibited migratory indices below this figure. All five patients who had shown a positive response to normal colonic mucosal extract also demonstrated marked inhibition of migration with tumour extract.

\section{CULTURE IN AUTOLOGOUS SERUM}

For the 15 control subjects the mean migratory index in response to normal colonic mucosal extract was 1.01 , the standard deviation of these results being 0.09 resulting in a lower 2.5 percentile figure of 0.83 . Of the 22 patients with colorectal cancer six showed migratory indices below this level, three of whom had also shown a significant inhibition of

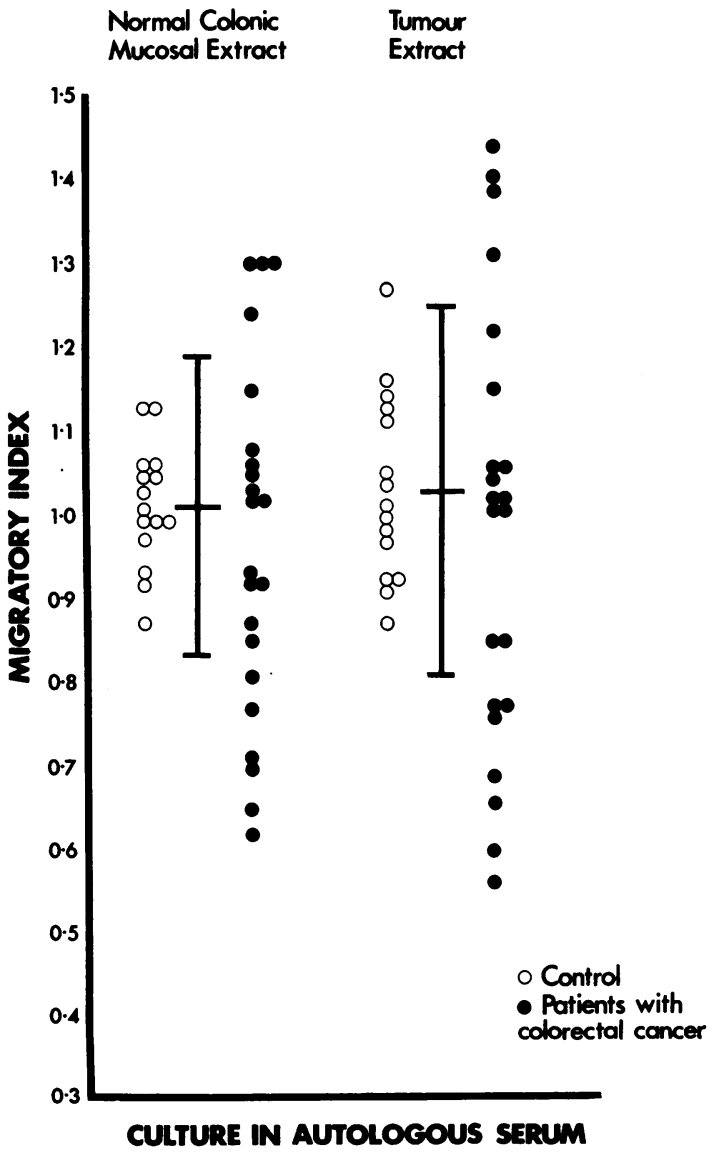

Fig 3 Leucocyte migratory indices obtained when culture performed in autologous serum. Vertical lines indicate the mean $\pm 2 \times$ standard deviations of the results obtained for control group of subjects. 
migration against normal colonic mucosal extract when cultured in homologous AB serum (fig 3).

For the control subjects a mean migratory index of 1.03 was obtained when their leucocytes were cultured in autologous serum in the presence of tumour extract. The standard deviation about the mean figure was 0.11 resulting in a lower 2.5 percentile limit of $0 \cdot 81$. In contrast with culture in homologous $A B$ serum only seven of the patients with cancer exhibited migratory indices which were below this figure. Thus out of 15 patients who had shown possible sensitization to the tumour extract when culture was performed in homologous $\mathrm{AB}$ serum only six of those showed significant inhibition of migration when culture was performed in autologous serum. This difference is statistically significant at the $1 \%$ level by Fisher's $\chi^{2}$ test. In addition the leucocytes of one patient who had not shown significant inhibition against tumour extract when culture was performed in homologous serum did show such inhibition when culture was performed in autologous serum.

\section{LEUCOCYTE MIGRATION INDICES IN EXCESS OF THE UPPER CONFIDENCE LIMITS OF CONTROL SUBJECTS}

\section{Culture in homologous $A B$ serum}

On exposure to normal colonic mucosal extract, one control subject and one patient with cancer had migratory indices above the $95 \%$ confidence limits of the results for the control subjects. The same patient with cancer showed excessive migration with tumour extract (fig 2).

\section{Culture in autologous serum}

In this instance four patients with cancer showed excessive migration with both normal colonic mucosal and tumour extracts. However, three of these patients had marked inhibition of leucocyte migration when cultured with tumour extract in homologous AB serum.

RELATIONSHIP OF THE LEUCOCYTE MIGRATORY INDEX TO TUMOUR EXTRACT TO THE EXTENT OF DISEASE

In only one patient was the carcinoma confined to bowel wall and in this patient the leucocyte migration index was 1.08 in homologous $\mathrm{AB}$ serum and 1.05 in autologous serum. The remaining 21 patients were divided into eight patients with locally advanced diseases (C cases) and 13 patients with disseminated cancer ( $D$ cases) (see table). In six of the eight grade $C$ cases leucocyte migration was significantly inhibited in the presence of tumour extract when cultured in homologous AB serum. Only three of these six cases

\begin{tabular}{|c|c|c|c|}
\hline \multicolumn{2}{|c|}{ Stages $B$ and $C$} & \multicolumn{2}{|l|}{ Stage $D$} \\
\hline \multicolumn{2}{|c|}{$\begin{array}{l}\text { Migratory Index (Tumour } \\
\text { Extract) in }\end{array}$} & \multicolumn{2}{|c|}{$\begin{array}{l}\text { Migratory Index (Tumour } \\
\text { Extract) in }\end{array}$} \\
\hline$A B$ Serum & Autologous Serum & $A B$ Serum & Autologous Serum \\
\hline $\begin{array}{l}0.94 \\
1.3 \\
0.72 \\
0.53 \\
0.66 \\
0.6 \\
0.7 \\
0.62 \\
1.08\end{array}$ & $\begin{array}{l}1.01 \\
0.77 \\
1.22 \\
1.44 \\
1.4 \\
0.85 \\
0.66 \\
0.77 \\
1.05\end{array}$ & $\begin{array}{l}0.73 \\
0.69 \\
0.69 \\
0.49 \\
0.31 \\
0.85 \\
0.89 \\
0.69 \\
0.91 \\
0.75 \\
0.81 \\
0.57 \\
0.72\end{array}$ & $\begin{array}{l}0.6 \\
0.69 \\
0.56 \\
1.5 \\
1.31 \\
1.15 \\
1.02 \\
1.05 \\
1.04 \\
1.01 \\
0.85 \\
1.02 \\
0.76\end{array}$ \\
\hline
\end{tabular}

Table The relationship of the leucocyte migratory indices in homologous and autologous serum to the clinical extent of disease

showed inhibition when culture was performed in autologous serum. Of the 13 grade $D$ cases nine and four showed significant inhibition in homologous $\mathrm{AB}$ and autologous sera respectively.

\section{Discussion}

The inhibition of leucocyte migration results from the release of a soluble lymphocyte mediator (migratory inhibitory factor) from sensitized lymphocytes on exposure to antigen (Pick and Turk, 1972). Thus a positive test reflects cellular immunity towards a particular antigen. The technique has been previously applied to the demonstration of cellular immunity against human breast neoplasms (Andersen, Bjerrum, Bendixen, Schiødt, and Dissing, 1970), malignant melanoma (Cochran, Spilg, Mackie, and Thomas, 1972), and a few patients with colon carcinoma (Wolberg, 1971). Though Wolberg (1971) reported that many tumours contain substances capable of inhibiting leucocyte migration, other workers (Cochran et al, 1972), including ourselves, have shown that provided the concentration of tumour-associated antigen is not excessive (in these experiments not greater than $150 \mu \mathrm{g}$ protein per $\mathrm{ml}$ ), then leucocytes migrate normally. Thus under these experimental conditions a reduced area of leucocyte migration may be indicative of cellular immunity to tumour antigens.

In control subjects the leucocyte migratory index varies about a value of 1.0 on exposure to the normal colonic mucosal extract and tumour extract. Using the control subjects to establish the $95 \%$ confidence limits of the migratory indices in response to the normal colonic and tumour extracts, it was possible to pick out those patients with values below these 
limits in whom definite migratory inhibition had occurred.

Significant inhibition of leucocyte migration, and thus sensitization to tumour antigen, was demonstrated in 16 of the 22 patients whom we have investigated. In 15 of these patients positive tests were observed on culture in homologous $\mathrm{AB}$ serum and in an additional patient on culture in autologous serum. However, significant inhibition of migration was also found in eight patients when their leucocytes were exposed to the normal colonic mucosal extract. The reason for this finding is not immediately obvious but clearly could be related to the use of apparently normal colonic mucosa taken from patients with carcinoma elsewhere in the colon. In this case the contamination of the normal colon samples with tumour-associated antigen would be possible. It has also been shown that the highly purified tumour extract, carcinoembryonic antigen (CEA), can be found in relatively high concentration in inflamed non-cancerous colonic mucosa (Martin and Martin, 1972). It is possible therefore that some of the patients apparently sensitized to normal colonic mucosal extract are in fact showing delayed hypersensitivity reactions to tumour-associated antigens. It is of interest that in this study the proportion of patients with apparent sensitization to tumour extract is similar to that found by other investigators in breast cancer (Andersen et al, 1970) and melanoma (Cochran et al, 1972).

Sensitized lymphocytes are capable of releasing other lymphokines on exposure to antigen (Dumonde, 1970). The release of one of these soluble mediators (macrophage spreading factor) might explain the observation in this work that the leucocytes of one patient cultured in AB serum and of four patients in autologous serum, exhibited increased areas of migration on exposure to both normal colonic mucosal and tumour extracts. Of these four patients, three showed marked inhibition of migration in response to tumour extract when culture was performed in homologous AB serum. The implications of this observation are speculative but might indicate that humoral factors in the serum of patients with colorectal cancer are capable of selectively blocking the activity of the migratory inhibitory factor while leaving the activity of the macrophage spreading factor relatively unimpaired.

It has been suggested that the tumour host may be capable of producing antibodies which are able to block the cytotoxic effect of sensitized lymphocytes on the target cells (Hellström, Hellström, and Sjögren, 1971). Experimental animal tumour studies have been reported which support this view (Halliday, 1971). The presence of such antibodies would explain the observation that of the 15 patients in this series who demonstrated possible sensitization to the tumour extract when leucocyte culture was performed in homologous $\mathbf{A B}$ serum, nine were nullified by culture in autologous serum. An alternative explanation of these observations might be that circulating antigen is responsible for blocking the immunity exhibited in control serum. Currie and Basham (1972), using a microcytotoxicity assay in which lymphocytes were washed to varying degrees, have demonstrated that the serum component which was responsible for blocking the cytotoxic effect of the lymphocytes appeared to have an affinity for the lymphocyte surface, implying that the active principle was antigen rather than 'blocking' antibody.

Again using the technique of lymphocyte cytotoxicity, Currie, Lejeune, and Fairley (1971) suggested that the presence of cytotoxic lymphocytes in patients with malignant melanoma may be correlated with the tumour load. Hence those patients whose disease was minimal possessed circulating cytotoxic lymphocytes whilst those with extensive disease did not. A similar attempt to correlate tumour load with the in-vitro expression of delayed hypersensitivity to tumour extract has also been made in this study. Of the nine patients whose disease was confined to purely local spread (Dukes' classifications B and C) six showed possible sensitization. However, a similar proportion, nine of 13 patients who had disseminated disease (Dukes' classification D), also exhibited in vitro delayed hypersensitivity to tumour extract. Likewise there appeared to be no correlation between the extent of disease and the number of patients whose inhibition of migration was prevented by culture in autologous serum, namely, four out of six patients in groups B and C compared with five out of nine patients in group $\mathrm{D}$.

Thus even in the presence of advanced disease it would appear that lymphocytes which are sensitized to antigens present in colorectal adenocarcinomata continue to circulate in the tumour-bearing patient. Whatever its nature, the serum factor which blocks the manifestation in vitro of this sensitization appeared in this series to be unrelated to the extent of disease.

\section{References}

Andersen, V., Bjerrum, O., Bendixen, G., Schiødt, T., and Dissing, I. (1970). Effect of autologous mammary tumour extracts on human leukocyte migration in vitro. Int. J. Cancer, 5, 357-363. Cochran, A. J., Spilg, W. G. S., Mackie, R. M., and Thomas, C. E. (1972). Post-operative depression of tumour-directed cellmediated immunity in patients with malignant disease. Brit. med. J., 4, 67-70.

Currie, G. A., and Basham, C. (1972). Serum mediated inhibition of the immunological reactions of the patient to his own tumour: a possible role for circulating antigen. Brit. J. Cancer, 26, 427-438. 
Currie, G. A., Lejeune, F., and Fairley, G. H. (1971). Immunization with irradiated tumour cells and specific lymphocyte cytotoxicity in malignant melanoma. Brit. med. J., 2, 305-307.

Dukes, C. E. (1957). Discussion on major surgery in carcinoma of the rectum with or without colostomy, excluding the anal canal and including the rectosigmoid. Proc. roy. Soc. Med., 50, 1031-1035.

Dumonde, D. C. (1970). 'Lymphokines': Molecular mediators of cellular immune responses in animals and man. Proc. roy. Soc. Med., 63, 899-902.

Freed, D. L. J., and Taylor, G. (1972). Carcinoembryonic antigen in faeces. Brit. med. J., 1, 85-87.

Gold, P., and Freedman, S. O. (1965). Specific carcinoembryonic antigen of the human digestive system. J. exp. Med., 122, 467-481.

Halliday, W. J. (1971). Blocking effect of serum from tumor-bearing animals on macrophage migration inhibition with tumor antigen. J. Immunol., 106, 855-857.

Hellström, I., Hellström, K. E., Evans, C. A., Heppner, G. M., Pierce, G. H., and Yang, J. P. S. (1969). Serum mediated protection of neoplastic cells from inhibition by lymphocytes immune to their tumour specific antigens. Proc. nat. Acad. Sci. (Wash.), 62, 362-369.

Hellström, I., Hellström, K. E., Pierce, G. H., and Yang, J. P. S. (1968). Cellular and humoral immunity to different types of human neoplasms. Nature (Lond.), 220, 1352-1354.

Hellström, I., Sjögren, H. O., Warner, G., and Hellström, K. E. (1970). Blocking of cell-mediated tumor immunity by sera from patients with growing neoplasms. Int. J. Cancer, 7, 226-237.

Hellström, I., Hellström, K. E., and Sjögren, H. O. (1971). Some recent information on 'blocking antibodies' as studied in vitro. Transplant. Proc., 3, 1221-1227.

Kleinman, M. S., Harwell, L., and Turner, M. D. (1971). Studies of colonic carcinoma antigens. Gut, 12, 1-10.

Lejtenyi, M. C., Freedman, S. O., and Gold, P. (1971). Response of lymphocytes from patients with gastrointestinal cancer to the carcinoembryonic antigen of the human digestive system. Cancer (Philad.), 28, 115-120.

Lowry, O. H., Rosebrough, N. J., Farr, A. L., and Randall, R. J. (1951). Protein measurement with the folin-phenol reagent. J. biol. Chem., 193, 265-275.

Martin, F., and Martin, M. S. (1972). Radioimmunoassay of carcinoembryonic antigen in extracts of human colon and stomach. Int. J. Cancer, 9, 641-647.

Nairn, R. C., Fothergill, J. E., McEntegart, M. G., and Porteous, I. B. (1962). Gastro-intestinal specific antigen: an immunohistological and serological study. Brit. med. J., 1, 1788-1790.

Nairn, R. C., Nind, A. P. P., Guli, E. P. G., Davies, D. J., Rolland, J. M., McGiven, A. R., and Hughes, E. S. R. (1971). Immunological reactivity in patients with carcinoma of the colon. Brit. med. J., 4, 706-709.

Pick, E., and Turk, J. L. (1972). The biological activities of soluble lymphocyte products. Clin. exp. Immunol., 10, 1-23.

Rosenberg, S. A., and David, J. R. (1970). Inhibition of leucocyte migration: an evaluation of this in vitro assay of delayed hypersensitivity in man, to a soluble antigen. J. Immunol., 105, 1447-1452.

Wolberg, W. H. (1971). Inhibition of migration of human autogenous and allogeneic leucocytes by extracts of patients cancers. Cancer Res., 31, 798-802. 